\title{
GAME TYPE AS A MODERATOR OF THE RELATIONSHIP BETWEEN PATHOLOGICAL VIDEO GAME USE, IMPULSIVITY, AGGRESSION, AND GENERAL PSYCHOPATHOLOGY
}

\author{
A Thesis \\ by \\ MICHALE S. SFERRA \\ Submitted to the Office of Graduate and Professional Studies of \\ Texas A\&M University \\ in partial fulfillment of the requirements for the degree of \\ MASTER OF SCIENCE
}

Chair of Committee,

Committee Members,

Head of Department,
Sherecce Fields

Douglas Gentile

Leslie Morey

Srividya Ramasubramanian

Heather Lench

December 2016

Major Subject: Psychology

Copyright 2016. Michale S. Sferra 


\begin{abstract}
Previous research has established that Pathological Video Game Use (PVGU) is related to various psychosocial variables such as impulsivity, aggression, and other forms of psychopathology. However, not much is known about whether the genre of video game played most often by the gamer influences the aforementioned relationships. The purpose of the current study is to expand upon our knowledge by investigating the role of preference for particular genres of video games, either Massively Multiplayer Online Role Playing Games (MMORPG) or First Person Shooters (FPS) for the current study, as a moderator of the relationship between symptoms of PVGU and levels of impulsivity, levels of aggression, and reported symptoms of depression and anxiety. 932 undergraduate students recruited through Iowa State University's undergraduate research management system filled out measures querying media use behaviors, symptoms of PVGU, impulsivity, aggression, and symptoms of depression and anxiety.

Results of regression analyses revealed that participants who endorsed more symptoms of PVGU also reported increased levels of impulsivity measured via the BIS-11 $[\mathrm{R} 2=.033, \mathrm{~F}(2,871)=15.066, \mathrm{p}=$ $.000]$, increased levels of aggression $[\mathrm{R} 2=.101, \mathrm{~F}(3,872)=32.498, \mathrm{p}=.000]$, greater number of symptoms of depression $[\mathrm{R} 2=.028, \mathrm{~F}(2,869)=19.343, \mathrm{p}=.000]$, increased levels of state anxiety $[\mathrm{R} 2=$ $.028), \mathrm{F}(2,861)=12.547, \mathrm{p}=.000]$, and increased levels of trait anxiety $[\mathrm{R} 2=.040, \mathrm{~F}(2,860)=17.827, \mathrm{p}$ $=.000]$. Follow-up moderator regression analyses revealed that video game genre did not moderate the aforementioned relationships between PVGU and psychosocial outcome variables. In conclusion, those who endorsed a greater number of symptoms of PVGU also reported increased levels of impulsivity, aggression, symptoms of depression, and levels of both state and trait anxiety. However, these relationships were not moderated by preference for video game genre, suggesting that these relationships occur regardless of genre preference.
\end{abstract}




\section{ACKNOWLEDGEMENTS}

I would like to thank my committee chair, Dr. Sherecce Fields, and my committee members, Dr. Douglas Gentile, Dr. Leslie Morey, and Dr. Srividya Ramasubramanian for their guidance and support throughout the course of this research.

Thanks also go to my friends and colleagues and the department faculty and staff for making my time at Texas A\&M University a great experience.

Finally, thanks to my mother, father, and sister for their support and encouragement throughout this process. 


\section{CONTRIBUTORS AND FUNDING SOURCES}

\section{Contributors}

This work was supervised by a thesis committee consisting of my primary research advisor, Dr. Sherecce Fields, and Dr. Leslie Morey, both of whom serve in the Department of Psychology at Texas A\&M, Dr. Srividya Ramasubramanian of the Department of Communication at Texas A\&M, and Dr. Douglas Gentile of the Department of Psychology at Iowa State University.

The data analyzed for this project was provided by Dr. Douglas Gentile of the Department of Psychology at Iowa State University. All other work conducted for the thesis was completed by the student under advisement of Dr. Sherecce Fields and Dr. Douglas Gentile.

\section{Funding Sources}

There are no outside funding contributions to acknowledge related to the research and compilation of this document. 


\section{TABLE OF CONTENTS}

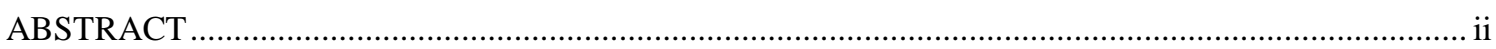

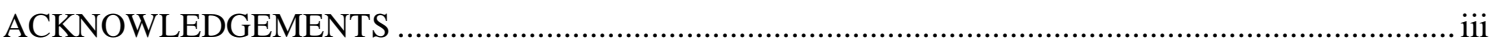

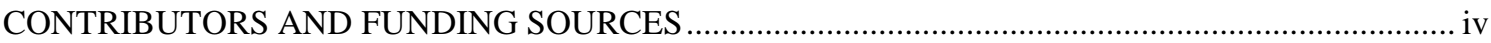

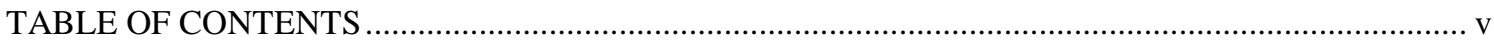

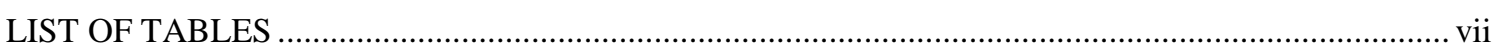

INTRODUCTION

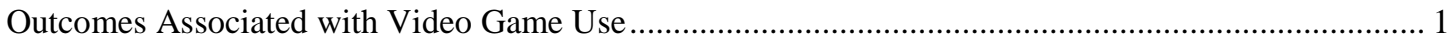

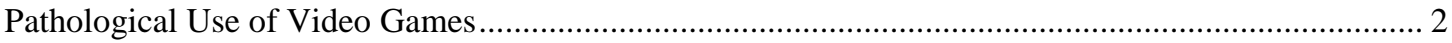

Conceptualizations and Definitions of Pathological Video Game Use ................................................... 3

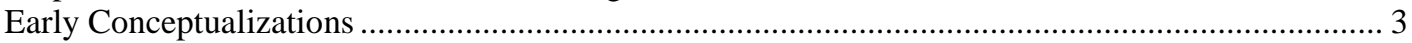

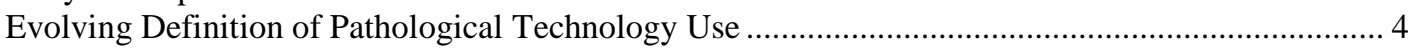

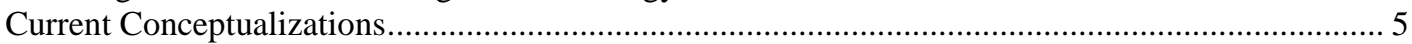

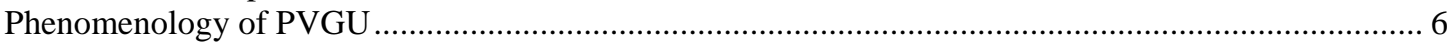

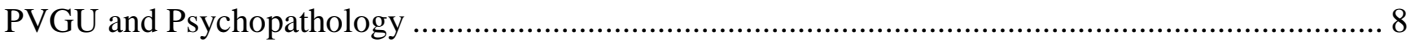

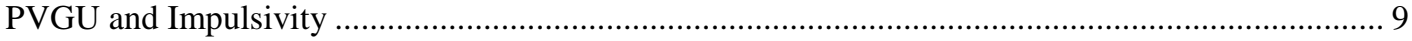

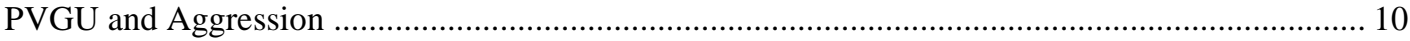

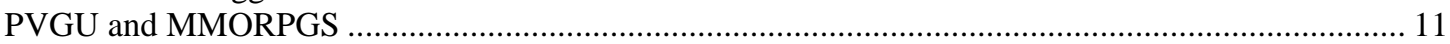

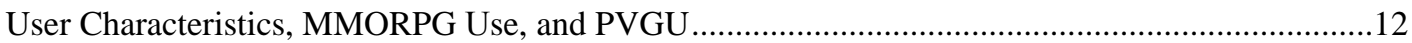

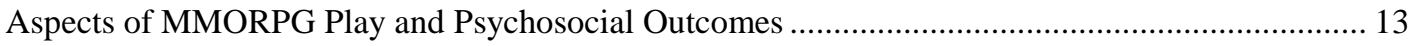

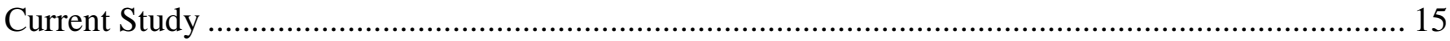

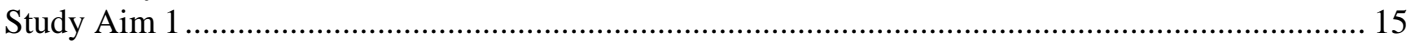

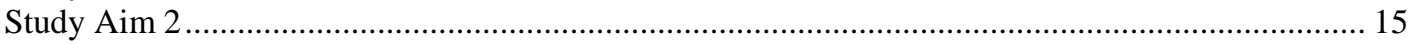

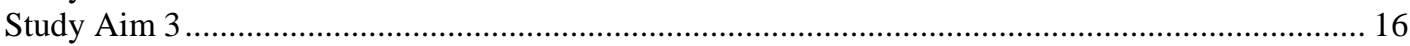

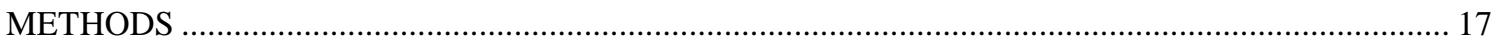

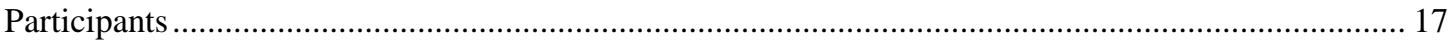

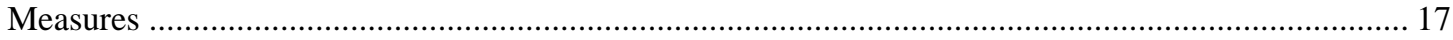

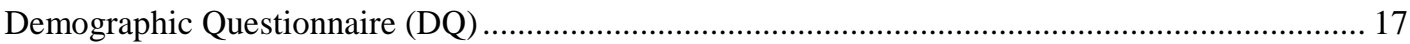

General Media Habits Questionnaire (GMHQ; Gentile, Lynch, Linder, \& Walsh, 2004) ................. 17

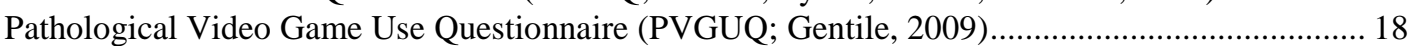

Barratt Impulsiveness Scale (BIS-11; Patton, Stanford, \& Barrat, 1995 ......................................... 18

Sensation Seeking Scale Form V (SSS; Zuckerman, Eysenck, \& Eysenck, 1978)............................ 18

Academic Delay of Gratification Scale (ADOGS; Bembenutty \& Karabenick, 2004) ...................... 19

Center for Epidemiologic Studies Depression Scale (CES-D; Radloff, 1977) ................................... 19

Buss-Perry Aggression Questionnaire (AQ; Buss \& Perry, 1992) ................................................... 19

Spielberger State-Trait Anxiety Inventory (STAIX, Spielberger, Gorsuch, \& Lushene, 1970) ........ 20

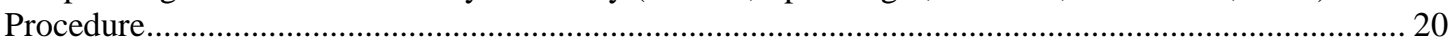

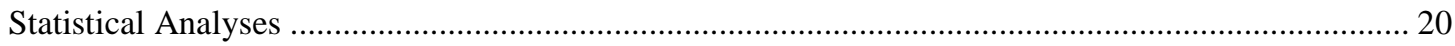




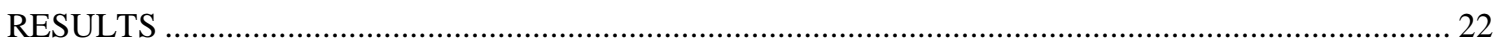

Participant Characteristics ...................................................................................................... 22

ANCOVA Analyses for Video Game Genre Preference and Psychosocial Outcomes ........................ 23

Regression Analyses for PVGU as Predictor of Impulsivity, Aggression, and Psychopathology .......... 24

Video Game Genre as Moderator of PVGU and Psychosocial Outcomes ....................................... 24

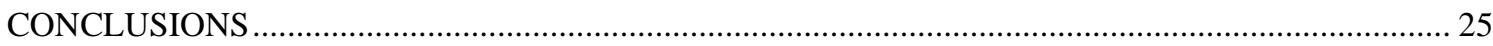

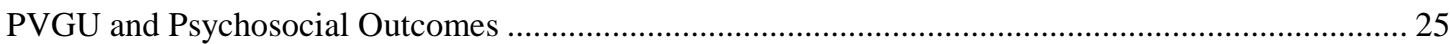

Preference for Video Game Genre and Psychosocial Outcomes ................................................. 28

Moderating Effects of Preference for Video Game Genre .................................................... 29

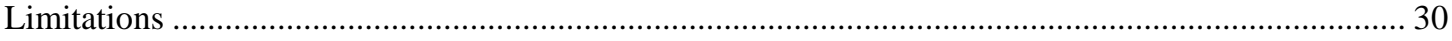

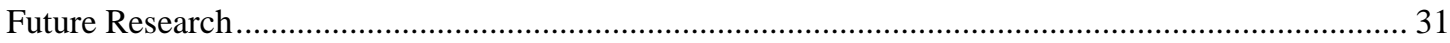

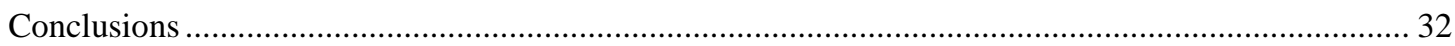

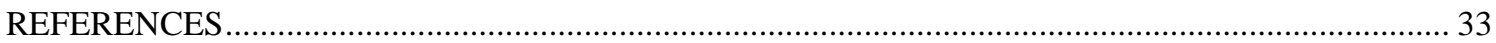

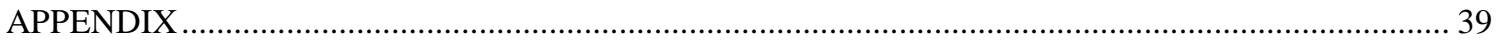




\section{LIST OF TABLES}

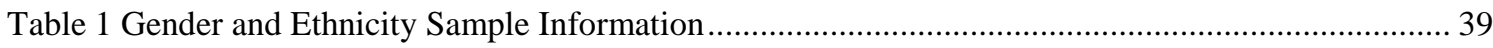

Table 2 Regression Analyses: Age as Predictor of Psychosocial Variables........................................ 40

Table 3 ANOVA for Gender and Ethnicity x Psychosocial Variables ............................................. 41

Table 4 ANCOVA for Preference for Video Game Genre x Psychosocial Variables............................ 42

Table 5 Regression Analyses: PVGU as Predictor of Psychosocial Outcome

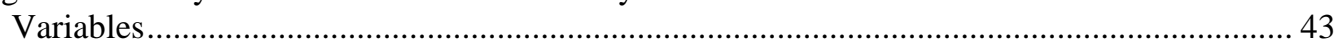

Table 6 Means, Standard Deviations, and Correlations for Psychosocial Variables ............................... 44

Table 7 Moderator Analyses for Preference for Interaction of Video Game Genre and PVGU x Psychosocial Outcome Variables 


\section{INTRODUCTION}

Technology has become an integral part of the lives of many individuals over the past two decades due in no small part to the advances in the capabilities and accessibility of digital technologies. One use of these technologies, the recreational use of video games, has rapidly permeated the lives of people all across the world. In the U.S. specifically, $63 \%$ of Americans report having played a video game in the past six months, outnumbering those who have gone out to see a movie (Graham, 2009). In 2013, U.S. consumers spent nearly $\$ 21$ billion on video games, hardware, and accessories (Entertainment Software Association, 2013). Furthermore, the average U.S. household reportedly owns at least one dedicated gaming console, PC, or smartphone. Furthermore, for those households that do own a dedicated game console, they own an average of two (ESA, 2013).

The recreational use of video games is a hobby that spans across all ages and genders. Although video game use is a pastime typically associated with adolescence, industry reports found that the average age of game players is 30 and that the largest section of players are over the age of $36(36 \%)$, followed closely by players between the ages of 18 and $35(32 \%)$ and players under the age of 18 (32\%; ESA, 2013). Historically, video game use has also been associated with being male - however, the ESA (2013) reports that as many as $45 \%$ of people who play video games are female.

\section{Outcomes Associated with Video Game Use}

The growing trend of video game use over the past couple decades has garnered the attention of various researchers, many of whom have focused their efforts on both the positive and negative health correlates of video game use in both adolescent and adult populations. One such survey in adolescents found that $51 \%$ of high school students reported that they play video games ( $76 \%$ for males only), and that gaming was associated with (1) never having used marijuana or smoking in males, (2) higher grade point averages in males, and (3) never having used marijuana or alcohol in females (Desai, Krishnan-Sarin, Cavallo, \& Potenza, 2010). In another study of positive associations with video game use by Durkin and Barber (2002), researchers found that adolescents who played computer games reported less substance abuse, were less likely to disobey their parents on an important issue, and reported having closer family relationships than those who did not play computer games. Indeed, given the high prevalence rate of video 
game use in adolescents, this behavior may be normative for many and serve as a way for adolescents to relate to their peers.

However, there has been some research on the negative health correlates of video game use. One such study found that video game use habits (e.g., length of play during one sitting, frequency of play, years of playing games) were negatively associated with healthy exercise habits (e.g., frequency of exercise, duration of exercise sessions) and associated with higher Body Mass Index (BMI) values in a sample of undergraduate males (Ballard, Gray, Reilly, \& Noggle, 2009). These relationships were particularly strong in players of online video games, specifically Massively Multiplayer Online Role Playing Games.

Similar results regarding negative health outcomes were found using a sample of adults who play video games, where female players reported poorer perceived health status and male players reported higher BMI values than non-players of both genders (Weaver, Mays, Weaver, Kannenberg, Hopkins, et al., 2009). Further still, other researchers have examined the effects of the use of video games that are violent in nature on a sample of 8th- and 9th- grade student players and found that adolescents who exposed themselves to greater amounts of video game violence were more likely to engage in hostile behaviors at school such as being involved in physical fights and getting into arguments with teachers (Gentile, Lynch, Linder, \& Walsh, 2004).

\section{Pathological Use of Video Games}

Although it is important to acknowledge that for the vast majority of individuals video game use is not problematic or pathological, and may in fact be associated with positive outcomes, there appears to be a point at which a person's use of video games may become pathological. In order to understand how to incorporate video games into a healthy lifestyle, it is necessary to understand what factors are associated with a pattern of pathological video game use. In regards to pathological use, a national study of over 1,100 youth ages 8 to 18 found that as many as $8.5 \%$ of adolescent video game players exhibited pathological patterns of video game play, with pathological gamers spending twice as much time playing video games, receiving poorer grades in school, and experiencing higher rates of attention problems than adolescents whose use was not pathological (Gentile, 2009). The aforementioned study utilized a measure 
of pathological gaming adapted from the Diagnostic and Statistical Manual of Mental Disorders - Fourth Edition (DSM-IV; American Psychiatric Association, 1994) criteria for pathological gambling, and found similar prevalence rates to those reported from other studies carried out internationally (Sim, Gentile, Bricolo, Serpelloni, \& Gulamoydeen, 2012). This prevalence rate is concerning given previous research findings suggesting that PVGU may be comorbid with several other problematic behaviors such as substance use disorders, mood disorders, anxiety, social phobia, and depression (Black, Belsare, \& Schlosser, 1990; Gentile, 2009; Gentile, Choo, Liau, Sim, Fung, et al., 2011; Yoo, Cho, Ha, Yune, Kim, et al., 2004).

Although findings linking pathological patterns of video game use with psychosocial outcomes have been frequently documented in the literature, there has been some debate over the past two decades regarding reaching a consensus on how to define, measure, and conceptualize pathological video game use - a consensus that is required if we wish to continue to advance the field as a whole (Sim, et al., 2012).

\section{Conceptualizations and Definitions of Pathological Video Game Use Early Conceptualizations}

There has been considerable debate over the past two decades as to whether or not a sustained pattern of video game or general technology use that has become problematic for an individual in terms of their psychosocial functioning should be considered a psychological disorder (Blaszczynski, 2006; King, Delfabbro, \& Zajac, 2011; Wood, 2008). Historically, this debate has been further complicated by the lack of a standardized, generally-accepted set of descriptive terms and diagnostic criteria for assessing Pathological Technology Use (PTU; Petry et al., 2014; Sim et al., 2012), although researchers and clinicians have recently begun to make great strides towards reaching an international consensus in this regard (King, Haagsma, Delfabbro, Gradisar, \& Griffiths, 2013; Petry et al., 2014).

Many different criteria for measuring PTU (or a subset of PTU, Pathological Video Game Use; PVGU) have been proposed, most of which have been derived from either the Diagnostic and Statistical Manual of Mental Disorders - Fourth Edition (DSM-IV; American Psychiatric Association, 1994) substance abuse criteria, existing DSM-IV-based pathological gambling criteria, or Brown's criteria for addiction - all of which reportedly share many common characteristics (Wood, 2008; American 
Psychiatric Association, 2000). One of the earliest conceptualizations of pathological technology use was introduced in 1998 by Young, who wrote about the emergence of a new clinical disorder which she termed "Internet Addiction." In her article, she attempted to develop a set of diagnostic criteria to assess internet addiction that was heavily based off of DSM-IV criteria for Pathological Gambling, another behaviorally based "addiction."

Her measure included eight criteria, where participants who answered "yes" to five or more of the criteria were considered pathological in their use. Young's (1998) criteria included (1) preoccupation with the Internet, (2) needing to spend increasing amounts of time on the Internet in order to achieve satisfaction, (3) making unsuccessful attempts to stop or cut back amount of use of the Internet, (4) feeling restless, moody, or irritable when attempting to cut down use of the Internet, (5) staying online longer than originally intended, (6) jeopardizing or risking the loss of a significant relationship, job, or educational opportunity because of Internet use, (7) lying to others to conceal the extent of Internet use, and (8) using the Internet as a means of escaping from problems or relieving dysphoric mood.

\section{Evolving Definition of Pathological Technology Use}

This initial conceptualization of PTU as a behavioral addiction was met with some controversy from the scientific community. Some authors felt that using the term "addiction" to describe this pattern of behavior may be both inappropriate and misleading given the connotations typically associated with more traditional addictions such as those based on drug use (Woods, 2008). Other researchers suggest that pathological technology use might be better conceptualized as an impulse-control disorder rather than an "addiction" (Holden, 2001).

In response to the controversy surrounding the use of the term "addiction" to describe this behavioral syndrome, several alternative labels for this syndrome have been proposed: Internet Use Disorder, Compulsive Internet Use, Problematic Internet Use, Online Game Addiction, and Internet Gaming Disorder (King et al., 2013; Petry et al., 2014). Although most of these conceptualizations share many common themes and diagnostic criteria, researchers and clinicians have begun to recognize the need for a standardized set of criteria if the field as a whole wishes to progress in its ability to both identify and treat PTU / PVGU (Sim et al., 2012). 


\section{Current Conceptualizations}

With the inclusion of Internet Gaming Disorder (IGD) as a diagnosis in the research appendix of the most recent edition of the Diagnostic and Statistical Manual of Mental Disorders - Fifth Edition (DSM-V; American Psychiatric Association, 2013), the field seems to be making some strides in regards to reaching a consensus on diagnoses. In order for an individual to classify for a diagnosis of IGD using the DSM-V, they must present with five or more of the following nine symptoms within a 12 -month period: (a) preoccupation with internet games, (b) withdrawal symptoms related to gaming, (c) tolerance in relation to gaming, (d) unsuccessful attempts to quit or reduce time spent gaming, (e) loss of interests in previous activities outside of gaming, (f) continued excessive use of games despite knowledge of psychosocial problems related to their use, $(\mathrm{g})$ has deceived others in order to conceal their amount of time spent gaming, (h) use of games to escape negative thoughts or feelings, and (i) has jeopardized or lost a significant relationship, job, educational or career opportunity because of playing video games.

Aside from the conceptualization proposed in the DSM-V, another promising alternative conceptualization, Pathological Technology Use (PTU), has recently been proposed by Sim and colleagues (2012). After conducting a thorough review of past research studies examining various conceptualizations and diagnostic criteria of PTU, or Pathological Video Game Use (PVGU) when the disorder deals primarily with the use of video games, the authors proposed a 10-item measure to be used for the classification of PVGU. These items assessed for (1) cognitive salience / preoccupation with video games, (2) the need to spend more time / money in order to achieve desired excitement, (3) unsuccessfully attempts to limit amount of time playing, (4) feeling restless or irritable when attempting to cut down time playing, (5) playing video games as a means to escape from problems, (6) lying to others to conceal amount of use, (7) committing illegal / unsocial acts in order to get video games, (8) neglecting chores / job duties to play games, (9) performing poorly on a school assignment or impairment of job performance due to video game use, and (10) needing financial assistance from others due to the amount of money spent on video games. Based on previous findings regarding the construct validity of PVGU and its associations with psychosocial outcomes, the authors suggest that individuals who endorsed five or more symptoms be classified as pathological in their use of video games. 
This alternative conceptualization (PTU / PVGU) is useful in many ways (Sim et al., 2012). First, it avoids the controversial use of the term "addiction" in its label. Second, it draws attention to the notion that technology is neither inherently good nor bad, but it is instead the nature of the use of technology that clinicians and researchers must consider when determining pathology. Third, the proposed criteria are based off of an amalgamation of past research demonstrating the construct validity of PVGU (Sim et al., 2012). Finally, it provides a framework which can be easily adapted to shift between the assessment of general pathological technology use or to focus on specific aspects of technology use such as the use of the Internet or the use of video games.

\section{Phenomenology of PVGU}

People engage in video game play for a variety of reasons. Some engage in video game play because it helps them to relax, to experience competency and autonomy, or to escape from reality (Ryan, Rigby, \& Przybylski, 2006; Gentile, 2009). Others engage in video game play because it provides them a sense of achievement through competition, or perhaps they find the social aspect of online games as rewarding (Yee, 2006). It is also possible as video game use grows in popularity as a pastime, more people see video game use as a social activity that they can share with friends whom they know in real life. There is also some evidence that players may experience a pleasurable experience call a "flow" state during their use (Chou \& Ting, 2003). During this flow state, the player becomes totally absorbed in the activity and experiences a sense of absolute control and enjoyment. The player can become so engrossed in the behavior producing this flow state that they experience a diminished sense of time (Csikzentmihalyi, 1990).

Although video game use is not pathological at first, for some people their use may reach a point where it can interfere with and cause significant problems in other areas of their life and daily functioning. The precise etiology of pathological video game use is currently unknown, but some researchers have begun to speculate about what risk factors may predispose someone to the development of PVGU and what mechanisms may drive someone to become pathological in their use (Sim, Gentile, Bricolo, Serpelloni, \& Gulamoydeen, 2012). 
In regards to the issue of what mechanisms and risk factors drive someone to become pathological in their use, The National Institute of Drug Abuse suggests that one useful framework might revolve around the balance between both risk and protective factors (Pickens \& Svikis, 1988). Using this vulnerability model, if the risk factors outweigh the protective factors for an individual, then the individual is at a greater likelihood to develop problems concerning their use.

In light of this model, it is helpful to examine what correlates of PVGU may exist to serve as risk factors for the development of PVGU. Gentile and colleagues (2011) conducted one of the few longitudinal studies to date in which they examined the course of PVGU in adolescents in Singapore over a two-year time period to determine such risk and protective factors. They found that several personality characteristics seemed to act as risk factors for the development of PVGU. Their results indicated that youths who (a) were more impulsive, (b) displayed lower levels of social competence and empathy, and (c) possessed poorer emotion regulation skills were all more likely to meet criteria for PVGU. The authors also point out that their findings support the notion that pathological gaming may best be conceptualized as an impulse control disorder, which is further supported by previous research indicating that youths whose video game use was pathological were also more likely to be diagnosed with ADHD (Gentile, 2009; Gentile et al., 2011).

Some researchers suggest that the experience of a flow state may predispose some individuals to become more pathological in their use of video games (Chou \& Ting, 2003). One study (Chou \& Ting, 2003) found that individuals who endorsed a greater number of indicators of state of flow during game play were also more likely to endorse more items thought to be symptomatic of PVGU. Furthermore, state of flow appeared to have a stronger relationship with PVGU than just repetition of the behavior (i.e., playing video games) alone, suggesting that time spent playing by itself is not a sufficient indicator for the presence of PVGU (Chou \& Ting, 2003).

Davis (2001) proposes an alternative model to conceptualizing the development of pathological technology use focused on maladaptive cognitions and patterns of reinforcement. In this cognitivebehavioral model of PTU, the individual first makes use of technology in such a way that they find some behavioral reinforcement that encourages them to repeat the behavior in the future (Davis, 2001). Pre- 
existing psychopathology, situational cues, and dysfunctions in domains of functioning such as a lack of social support may predispose the individual to seek out this reinforcement from technology while neglecting other important aspects of their life. Over time, the individual develops negative cognitions about themselves and the world that serve to further reinforce the pattern of pathological use in a vicious cycle (Davis, 2001).

\section{PVGU and Psychopathology}

Aside from previous research linking PVGU and facets of normal personality, researchers have also examined the comorbidity of PVGU with other psychological disorders. One literature review by Shapira and colleagues (2003) found that the most common psychological disorders that were found to be comorbid with problematic internet use were mood disorders, substance use disorders, impulse control disorders, and personality disorders. Specifically, in Shapira, Goldsmith, Keck, Khosla, and McElroy (2000), they found that $45 \%$ of individuals who were experiencing symptoms of PVGU had been diagnosed with either an alcohol or substance abuse / dependence disorder, $45 \%$ had been diagnosed with social phobia, and $60 \%$ had been diagnosed with bipolar I disorder at some point throughout their life.

In a 2004 study, Yoo and colleagues sought to evaluate the relationship between Attention Deficit-Hyperactivity Disorder (ADHD) and PTU in a sample of 535 South Korean elementary school students. Utilizing a measure of PVGU based off of Young's Internet Addiction test and the Korean translation of DuPaul's ADHD Rating Scale, Yoo and colleagues (2004) found that students who had higher scores on the scale of ADHD symptoms also tended to have higher scores on the measure of PVGU than students who had lower total scores on the measure of ADHD symptoms. These findings are in line with Gentile's 2009 national study of 1,178 American youths between the ages of 8 and 18, where his results indicated that pathological gamers were twice as likely as gamers who were nonpathological in their use to have been diagnosed with an attention problem, such as ADHD.

In the discussion of their results, Yoo and colleagues (2004) suggest that ADHD may be a contributing risk factor for developing PVGU insofar that use of the Internet may help to compensate for the associated interpersonal difficulties one may be expected to experience in tandem with ADHD. Individuals who experience many symptoms of ADHD may also be more likely to experience difficulties 
in their social interactions and turn to use of the Internet and video games as a coping mechanism, creating a vulnerability to go on to develop PVGU.

Returning once again to Gentile and colleagues' (2011) longitudinal study of Singaporean children and adolescents, their results provide evidence for the classification of PVGU as a distinct psychological disorder and not merely as a coping mechanism for more serious forms of psychopathology. In their study, the researchers found that initial pathological gaming symptoms and later increases in pathological gaming could be used to predict later increases in levels of depression, anxiety, and social phobia (Gentile et al., 2011).

\section{PVGU and Impulsivity}

Impulsivity, has received a great deal of attention from researchers of PVGU. This is not surprising, given that researchers have argued that PVGU should be conceptualized as an impulse-control disorder similar to the DSM-IV-TR classification of pathological gambling (Holden, 2001). One such study examined the role of self-regulation as a mediator of the relationship between impulsivity and PVGU among primary and secondary school students in Singapore (Liau et al., 2011). They found that self-regulation served as a moderator of the aforementioned relationship, where students who were high on levels of impulsivity and low on levels of self-regulation tended to have higher levels of PVGU (Liau et al., 2011). A similar study conducted by Meerkerk, van den Eijnden, Franken, and Garretsen (2010) found that spontaneous impulsivity may actually serve as a better predictor of Compulsive Internet Use (CIU) than other psychosocial wellbeing factors such loneliness, life satisfaction, and depressed mood in an online sample of adult 'heavy users' of the Internet.

Similarly, Gentile, Swing, Lim, and Khoo (2012) examined the relationship between attention problems, impulsiveness, and PVGU in a sample of 3,034 children and adolescents from Singapore over a period of 3 years. Consistent with previous research, they found that children who were exposed to greater levels of video game play also experienced greater problems with attention and impulsivity later on, even when controlling for earlier levels of both attention and impulsivity.

Additionally, a meta-analysis conducted by Kuss and Griffiths (2012) commented on the relationship between PVGU and aspects of impulsivity. They discovered that several factors thought to be 
related to impulsivity, such as boredom inclination, sensation seeking, and diminished self-control, were all found to be associated with higher levels of PVGU (Chiu, Lee, \& Huang, 2004; Kim, Namkoong, Ku, \& Kim, 2008). All of these findings point toward the conclusion that there exists a relationship between impulsivity and PVGU, and that future researchers should devote more resources to better understanding the dynamics of this relationship.

\section{PVGU and Aggression}

Aggression is another personality characteristic whose relationship with PVGU has garnered the attention of several researchers. For example, one study sought to explore the relationship between PVGU, aggression, and narcissistic personality traits in a sample of 1,471 users of online video games (Kim,

Namkoong, Ku, \& Kim, 2008). The researchers gathered participants from three popular MMORPG video game websites and administered the Online Game Addiction Scale (a modified version of Young's Internet Addiction Scale), the Buss-Perry Aggression Questionnaire, and the Narcissistic Personality Disorder Scale. Their results indicated that both aggression and narcissistic personality traits were positively correlated with PVGU (Kim et al., 2008). From their results, the authors postulated that players who scored higher on a measure of an aggressive trait may be more prone to engage in an online game as a way to express their aggressive impulses whose expression are not acceptable in the real world (Kim et al., 2008).

Returning to the earlier study by Gentile and colleagues (2011) in which they examined the relationship between PVGU and various psychosocial factors over a period of several years in a sample of Singaporean children and adolescents, it is also important to make note of their results in regards to the relationship between PVGU and aggression. The researchers found that once players became more pathological in their use over time, they also began to be exposed to more violent video games. Furthermore, children who were exposed to more violent video games began to (a) harbor normative beliefs about aggression, (b) experience aggressive fantasies, and (c) were more likely to express physically and relationally aggressive behaviors (Gentile et al., 2011).

Some researchers have begun to examine the relationship between aggression and exposure to a particular genre of violent video games known as First Person Shooters (FPS), a game in which the player 
navigates the digital world through the eyes of their avatar with the objective of shooting opponents (Schneider, 2004). Popular examples of this genre include Goldeneye, the Halo series, and the Call of Duty series. In a 2007 study, Barlett, Harris, and Baldassaro examined this relationship by asking participants to play a FPS video game and then comparing their scores on a measure of aggression both pre- and post-game play. They found support for their hypothesis insofar that participants who played the FPS displayed higher levels of aggression. The authors referred to the General Aggression Model as a possible explanation, suggesting that engaging in violent video games increased aggressive thoughts, which in turn increased aggressive behaviors (Barlett, Harris, \& Baldassaro, 2007; Bushman \& Anderson, 2002).

\section{PVGU and MMORPGS}

One video game genre that has received attention amongst researchers of PVGU are Massively Multiplayer Online Role Playing Games (MMORPGs), to which there are over 20 million active subscribers worldwide (White, 2012). The most popular MMORPG in the world, World of Warcraft, boasts nearly 8 million subscribers alone, with other notable examples of the genre including such titles as Lineage II, Star Wars: The Old Republic, and EVE Online (Karmali, 2013).

In a typical MMORPG, the player logs into a persistent, online, virtual world where they are able to create and control their own digital avatar as they perform a series of quests that provide their character with some form of reward (e.g., in-game currency, items, or experience points required to obtain new skills or abilities). As players progress through the game the quests often become harder, with some requiring as many as 40 players working together in a group in order to accomplish a single task. To facilitate the completion of these group quests, players will often join large, in-game organizations called "guilds." These guilds vary drastically in size, ranging from as few as a dozen to as many as a few hundred members (Williams et al., 2006). The amount of teamwork and social interaction required by these games introduces a social aspect that many users find compelling. Indeed, one survey of MMO players revealed that $44 \%$ of adolescents and $54 \%$ of adults rated the social component of the game as their favorite feature (Griffiths, Davies, \& Chappell, 2004). 
Charlton and Danforth (2009) suggest that MMORPGs possess several mechanisms that may make them particularly addictive for people who are already vulnerable to PVGU. One such mechanism they identify is the use of operant conditioning variable-ratio reinforcement (VR) schedules in most MMORPGs, which have been previously identified as a highly effective form of conditioning (Wallace, 1999), and thus may contribute to the addictive potential of these types of games. A second mechanism that may contribute to prevalence rates of PVGU among users of MMORPGs is the use of social reinforcement (Charlton \& Danforth, 2009). As players progress through these games a certain amount of pride and acclaim is afforded to those who obtain the best items, most of which can only be obtained through hard work, dedication, and a degree of skill. Charlton and Danforth (2009) go on to argue that this in-game acclaim may serve as social reinforcement for gamers who may not otherwise receive positive social reinforcements from their peers in their daily face-to-face interactions, thereby encouraging their continued use of the game as a way to get their interpersonal needs met.

\section{User Characteristics, MMORPG Use, and PVGU}

Given the mechanisms inherent in MMORPGs that may make their users more susceptible to the development of PVGU than users of other video games, researchers may find it useful to focus some of their efforts on examining the phenomenology of PVGU as it is presented in this unique population of video game users. If users of MMORPGs indeed turn out to be more susceptible to developing PVGU, this information would help to inform future intervention efforts targeting the prevention of the development of PVGU.

There is some evidence to suggest that certain personality characteristics may make individuals more likely to engage in MMORPG use in a pathological manner. Previous research by Peters and Malesky (2008) examined the relationship between symptoms of pathological video game use and responses on the NEO Personality Inventory-Revised (NEO-PI-R), a measure of the Big Five personality traits, within a sample of 204 players of World of Warcraft, a Massively Multiplayer Online Role Playing Game (MMORPG). The results of their study demonstrated that PVGU in a sample of MMORPG players possessed the following relationships with aspects of personality: (1) a moderate negative correlation with agreeableness, (2) a moderate positive correlation with neuroticism, (3) a small negative correlation with 
extraversion, and (4) a small negative correlation with conscientiousness. The authors suggest that, given that four of the five-factor model personality characteristics displayed a statistically significant correlation with PVGU, there may be a specific constellation of personality characteristics that make an individual who plays MMORPGs susceptible to the development of PVGU.

In light of their results, Peters and Malesky (2008) suggest that a player who is both low on agreeableness and high on neuroticism may wish to avoid social situations in which they lack the proper skills to facilitate the positive development of those relationships, and furthermore, may fear the possibility of rejection associated with the unsuccessful navigation of their peer relationships. However, the individual still may place some value on social interaction, as evidenced by the presence of only a weak negative correlation with extraversion in this study, so they seek out an avenue for social interaction that appears less constraining and threatening to them (i.e., socializing in an online video game; Peters \& Malesky, 2008). This may cause some individuals to become dependent on MMORPG as a way to meet their needs for social interaction as opposed to developing relationships in the real world. It is possible that this behavior pattern lends itself to developing a maladaptive pattern of use of these types of video games in particular.

\section{Aspects of MMORPG Play and Psychosocial Outcomes}

In 2012, Collins, Freeman, and Chamarro-Premuzic examined the relationship between symptoms of PVGU across various types of games and related psychosocial outcomes using a sample of 225 participants who were administered measures of PVGU and several personality traits (e.g., impulsivity, self-regulation, aggression). The researchers found that the group of participants who (a) played MMORPGs and (b) whose use was considered problematic tended to score lower on selfregulation, agreeableness, and dysfunctional impulsivity than participants who played MMORPGs but whose use was not considered problematic. Additionally, the same group of MMORPG players whose use was problematic also tended to score higher on both verbal and physical aggression, but lower on impulsivity, than non-MMORPG players (Collins, Freeman, \& Chamarro-Premuzic, 2012).

Given previous research linking PVGU to impulsivity (Liau et al., 2011; Meerkerk et al., 2010; Gentile et al., 2012), Collins and colleagues (2012) remarked that their findings regarding the relationship 
between PVGU and impulsivity that was found in players of MMORPGs may be influenced by aspects inherent in the design of MMORPGs. The authors hypothesized that impulsivity may in fact be detrimental to the development of PVGU in users of MMORPGs, seeing as impulsive actions in this genre of video game may cause an individual to experience negative ramifications from the game's environment (e.g., their character avatar dies repeatedly while trying to complete a quest). Additionally, MMORPGs do not typically allow a player to save his/her game and reload before a decision was made, which may serve to make the negative ramifications of impulsive decisions more salient on behalf of the player.

Although much of the discussion thus far concerning the social aspects of MMORPGs has focused on its pro-social qualities, such as fostering teamwork and cooperation, there are potentially antisocial elements of this type of game play well. There exists a subset of MMORPG players who frequently engage in behavior that intentionally causes grief to other players - for example, killing other player characters repeatedly, killing weaker "new" characters who pose no challenge, shouting hateful slurs or comments at other players despite being asked to stop, invading the personal space of other players and refusing to leave, or interfering with another player's attempt to complete a quest in some way (Foo \& Koivisto, 2004).

It is possible that some players are naturally drawn to this type of play style - such as those who are high on aggression and narcissism, two personality traits that have been found to be positively correlated with PVGU (Kim et al., 2008). Players who are then drawn to this style of play may find it reinforcing in some way and thus engage in these behaviors more frequently, setting up a cycle of reinforcement that serves to promote these anti-social behaviors. Over time, this cycle of reinforcement may cause the players to exhibit higher levels of aggression or other traits associated with anti-social behavior.

However, it may also be possible that the pro-social aspects of MMORPGs serve as a protective buffer against the effects of this reinforcement cycle of anti-social behavior. Perhaps players who spend some of their time engaging in anti-social video game behaviors and the rest of their time engaging in prosocial behaviors are less likely to experience problems that might be associated with anti-social gaming behaviors. Additionally, the mere existence of these type of anti-social behaviors may promote pro-social 
behaviors in others as a means of protection - for example, causing players to bond more closely to individuals that they trust in order to avoid being harassed by other players with whom they are unfamiliar (Foo \& Koivisto, 2004).

\section{Current Study}

Previous research has established the existence of a relationship between PVGU, psychopathology, impulsivity, and aggression. However, although research has previously examined the relationship between PVGU and some of the aforementioned factors within a population of a specific subset of video game players (i.e., MMORPG players), no research to date has sought to examine the role of preference for a particular genre of video game as a moderator of the relationship between symptoms of PVGU, psychopathology, impulsivity, and aggression. The current study seeks to both (1) examine the phenomenology of PVGU, general psychopathology, impulsivity, and aggression within different genres of video games, and (2) to examine whether preference for a particular video game genre plays a moderating role in the relationship between PVGU and the various aforementioned psychosocial outcome variables.

\section{Study Aim 1}

To examine whether symptoms of PVGU, levels of impulsivity, levels of aggression, and general psychopathology differ amongst participants as a factor of their reported preference for a particular genre of video game.

Hypothesis 1: Based on previous literature by Collins and colleagues (2012), it is hypothesized that participants who report a preference for MMORPG video games will score higher on symptoms of PVGU, levels of aggression, and general psychopathology, and lower on levels of impulsivity than participants who do not report a preference for MMORPG video games.

\section{Study Aim 2}

To examine the relationship between symptoms of PVGU, levels of impulsivity, levels of aggression, and general psychopathology.

Hypothesis 1: Participants who report more symptoms of PVGU will also report higher levels of impulsivity, aggression, and general psychopathology. 


\section{Study Aim 3}

To explore the role of preference for a particular type of video game as a moderator of the relationship between symptoms of PVGU and levels of impulsivity, levels of aggression, and general psychopathology.

Hypothesis 1: Preferences for playing a particular type of video game will serve as a moderator of the relationship between symptoms of PVGU, levels of impulsivity, levels of aggression, and general psychopathology. Based on previous research (Collins et al., 2012), it is hypothesized that individuals who report a preference for MMORPGs and report several symptoms of PVGU will score higher on measures of aggression and general psychopathology, and lower on measures of impulsivity, than individuals who do not prefer MMORPGs. 


\section{METHODS}

\section{Participants}

All participants were recruited through Iowa State University's undergraduate research management system. In order to be eligible for participation in the study, participants were required to be (a) at least 18 years of age and (b) a fluent, native English speaker. A total of 932 undergraduates (43\% female, $57 \%$ male) participated in the current study.

\section{Measures}

\section{Demographic Questionnaire $(D Q)$}

The DQ was designed to collect basic demographic information, including gender, age, ethnicity, academic performance, and general habits and interests concerning media use (e.g., time spent playing video games, types of video games played, etc.)

General Media Habits Questionnaire (GMHQ; Gentile, Lynch, Linder, \& Walsh, 2004)

The GMHQ is a self-report measure that directly asks participants about their habits and interests concerning various forms of media (e.g., television, video games). Only the following information gathered from the GMHQ will be included in the analyses for the current study: (a) amount of time spent playing video games on a typical day of the week, and (b) participant preferences for particular genres of video games (i.e., First Person Shooters, MMORPGs). Eight items in total were used to assess amount of time each participant spends playing video games on a typical weekday (i.e., Monday through Friday) and typical day of the weekend (i.e., Saturday or Sunday). These items require participants to specify how many hours (using 30 minute intervals) they play video games within four predetermined six-hour blocks of time, beginning with 6 a.m. through 12 p.m.

Preference for video game genre was ascertained by asking participants to identify three of their favorite video games, which were later classified by research staff according to genre. Following this, participants were then classified as reporting a preference for a particular genre of video game if one of their three reported favorite video games was listed as falling within that genre. The main genres of interest that were included in analyses were MMORPGs (e.g., World of Warcraft) and FPSs (e.g., Call of Duty). These genres were selected due to the fact that a knowledge base already exists concerning how 
these particular types of video games may influence individuals in terms of psychosocial outcomes such as aggression and impulsivity. They were also selected due to the unique characteristics inherent in each genre that may uniquely affect individuals along the constructs of interest for this study.

Pathological Video Game Use Questionnaire (PVGUQ; Gentile, 2009)

The PVGUQ is a 10-item self-report measure used to assess for the presence of symptoms of pathological video game use. Participants are asked to answer questions concerning their video game use and response using either "yes", "no", or "sometimes". A response of "yes" is scored as 1, a response of "no" is scored as 0 , and a response of "sometimes" is scored as 0.5 . Higher scores on this measure reflect the presence of a greater number of symptoms of pathological video game use. Previous research indicates acceptable reliability coefficients for this measure in young adult populations ( $\alpha=0.71$ to 0.79 ).

Barratt Impulsiveness Scale (BIS-11; Patton, Stanford, \& Barrat, 1995.

The BIS-11-A is a 30-item self-report measure used to assess impulsiveness. Impulsivity is measured based upon a total score that can be further divided into six first-order factors that have been identified as motor impulsiveness, cognitive complexity, self-control, cognitive instability, attention, and perseverance. Participants are asked to read a series of statements and indicate how often each statement applies to them using a four-point Likert scale with responses ranging from 1 ("rarely / never") to 4 (“almost always / always"). Higher total scores on this measure indicate greater levels of impulsivity. Previous research on the psychometrics of this measure indicates good internal reliability $(\alpha=0.83)$ with adult populations (Stanford et al., 2009). Examples of items presented on the BIS-11 include: I do things without thinking, I can only think about one thing at a time, I act on the spur of the moment.

Sensation Seeking Scale Form V (SSS; Zuckerman, Eysenck, \& Eysenck, 1978)

The SSS is a 40-item questionnaire that consists of 10 questions across each of four subscales: Thrill and Adventure Seeking (TAS), Experience Seeking (ES), Disinhibition (DIS), and Boredom Susceptibility (BS). Participants are asked to read two competing statements for each item and choose which statement better describes their likes or feelings. The responses across subscales are then summed to create a total Sensation Seeking score. Previous research on the psychometrics of this measure indicates good internal reliability, where reliability scores for the SSS total score ranged from 0.83 to 0.86 with 
adult populations (Zuckerman, Eysenck, \& Eysenck, 1978). An example item asks participants to choose between two options: (a) I prefer friends who are excitingly unpredictable or (b) I prefer friends who are reliable and predictable.

Academic Delay of Gratification Scale (ADOGS; Bembenutty \& Karabenick, 2004)

The ADOGS is a 10-item questionnaire in which respondents are presented with two options: (a) a more immediately available, gratifying reward with potential negative implications for academic performance, such as going to see a concert the night before an exam, or (b) an academic activity associated with a delayed, long-term, career-oriented reward, such as staying home to study for a test. Students are provided 10 forced choice alternative items and then asked to rate which alternative they would be most likely to engage in using a four-point Likert scale. Higher total scores on this measure reflect a greater tendency to delay gratification. Internal reliability scores from previous research range from 0.70 to 0.84 (Bembenutty, 1999; Bembenutty \& Karabenick, 2004).

Center for Epidemiologic Studies Depression Scale (CES-D; Radloff, 1977)

The CES-D is a 20-item self-report measure designed to identify levels of primarily affective and somatic symptoms of depression among the general population. Participants are provided with a series of items asking them to rate their frequency of symptoms of depression during the past week using a 4-point Likert scale ranging from "rarely" to "all of the time." Although no formal subscales for the CES-D exist, there are generally considered to be four factors tapped by the CES-D: Positive Affect, Depressed or Negative Affect, Somatic Symptoms, and Interpersonal Problems (Shafer, 2006). Previous research indicates good internal consistency ( $\alpha=0.85)$ using a sample of the general population (Radloff, 1977).

Buss-Perry Aggression Questionnaire (AQ; Buss \& Perry, 1992)

The AQ is a 29-item self-report measure purported to assess levels of aggression across four subscales: Physical Aggression, Verbal Aggression, Anger, and Hostility. Participants are provided selfdescriptive statements and asked to rate how characteristic that statement is of them using a seven-point Likert scale. Low scores indicate that the participant felt that the statement was extremely uncharacteristic of them, while high scores indicated that the statement was extremely characteristic. Previous research 
indicates acceptable levels of internal consistency for the AQ total score $(\alpha=0.89)$ and for each of the four subscales (ranging from $\alpha=0.72$ to 0.85 ; Buss \& Perry, 1992).

Spielberger State-Trait Anxiety Inventory (STAIX, Spielberger, Gorsuch, \& Lushene, 1970)

The STAIX is a 40-item self-report measure purported to assess two types of anxiety: state anxiety, which is thought to fluctuate in a person over time as a function of stressors placed on an individual, and trait anxiety, which is thought to reflect a relatively stable personality trait consisting of feelings of apprehension, tension, and increased activity within the individual. Participants are provided self-descriptive statements (20 pertaining to each type of anxiety) and asked to rate how characteristic each statement is of them using a four-point Likert scale. Higher scores indicate that the participant felt that the statement was more characteristic of them. Higher total scores for each of the two subscales reflect a greater degree of anxiety. Previous research indicates acceptable levels of internal consistency for total scores on both the state-anxiety $(\alpha=0.91)$ and trait-anxiety $(\alpha=0.89)$ subscales.

\section{Procedure}

All participants completed study measures online as part of a larger study examining the relationship between media-viewing habits and facets of personality. Primary measures included selfreported video game use behaviors, impulsivity, levels of aggression, symptoms of anxiety, and symptoms of depression. Measures were provided online via the Qualtrics system. Participants were sampled from undergraduate psychology courses and received credit for the completion of all measure through the Iowa State University’s SONA Experiment System. Experimental time for the measures used in the current study required approximately 90 minutes for each participant.

\section{Statistical Analyses}

To accomplish Specific Aim 1, participants were first categorized according to their reported preference for a particular type of video game (e.g., MMORPG, FPS) assessed via the GMHQ. Following this, multiple ANCOVA analyses were used to contrast participants in terms of their self-reported symptoms of pathological video game use (assessed via the PVGUQ), levels of impulsivity (assessed via the BIS-11, SSS, and ADOGS), levels of aggression (assessed via the AQ), and symptoms of 
psychopathology (assessed via the STAIX and CES-D) according to their preference for a particular type of video game while controlling for age, gender, and ethnicity when indicated.

To accomplish Specific Aim 2, multiple regression analyses were used to test the relationship between symptoms of PVGU, levels of impulsivity, levels of aggression, and psychopathology. PVGU were entered into the regression model as an independent variable for predicting impulsivity, aggression, and symptoms of psychopathology. Covariates included age, gender, and ethnicity when indicated.

To accomplish Specific Aim 3, moderator regression analyses were used to assess whether video game preference serves as a moderator of the relationship between symptoms of pathological video game use and self-reported levels of impulsivity, levels of aggression, and symptoms of psychopathology. Pathological video game use (assessed via the PVGUQ) and video game preference were entered into the regression model as predictors, as was their interaction. Self-reported impulsivity, aggression, and symptoms of psychopathology were entered into the model as dependent variables. All analyses were conducted using Statistics Package for the Social Sciences software (SPSS for Windows Version 20.0, 2011). The Bonferonni correction (Dunn, 1961) were utilized in all analyses in order to control for increased risk of type I error due to the use of multiple statistical analyses. 


\section{RESULTS}

\section{Participant Characteristics}

A total of 932 undergraduates ( $43 \%$ female, $57 \%$ male) participated in the current study.

Participants ranged in age from 18 to $50(M=19.65, S D=2.28)$. Most participants identified as White (74.7\%), followed by Asian / Pacific Islander (8.9\%), Latino / Hispanic (3.9\%), African American (3.1\%), and other $(1.8 \%)$. Ethnicity data is missing for 50 respondents. Demographic information for gender and ethnicity are presented in Table 1.

In response to the question "how often do you play video games," $15.3 \%$ of participants reported that they play almost every day, 27.4\% reported that they play between 2 to 5 times a week, $19.3 \%$ reported that they play between once a week and a couple times a month, $18.9 \%$ reported that they play video games about once a month or less, and $16.4 \%$ reported that they never play video games.

Participants who play video games reported playing video games for an average of 9.91 years $(S D=4.32)$, playing an average of 3.96 hours per week $(S D=5.61)$, and spending an average of 79.77 minutes playing video games in one sitting $(S D=63.29)$.

Ordinary least square regression analyses were used to determine whether age was significantly related to symptoms of PVGU, impulsivity, aggression, and symptoms of psychopathology (i.e., depression, anxiety). Age was positively related to symptoms of PVGU $\left[R^{2}=.008, F(1,880)=6.799, p=\right.$ .009], academic delay of gratification $\left[R^{2}=.009, F(1,872)=8.224, p=.004\right]$ and negatively related to the BIS-11 $\left[R^{2}=.006, F(1,872)=4.905, p=.027\right]$. Consequently, age was included as a covariate in all of the following analyses in which the aforementioned variables served as the dependent variable of interest. Results of regression analyses for age as a predictor of the aforementioned variables are presented in Table 2.

Several one-way ANOVA analyses were conducted to determine whether symptoms of PVGU, levels of impulsivity, levels of aggression, and symptoms of psychopathology varied by gender. There was a significant effect of gender such that males tended to endorse more of symptoms of PVGU $[F(1,879)=$ $149.79, p=.000]$ and higher levels of aggression $[F(1,874)=34.01, p=.000]$ and sensation seeking $[F(1,873)=58.84, p=.000]$. Females tended to endorse higher levels of academic delay of gratification 
$[F(1,871)=23.83, p=.000]$. Consequently, gender was included as a covariate in all of the following analyses in which the aforementioned variables served as the dependent variable of interest.

Additional one-way ANOVA analyses were conducted to determine whether symptoms of PVGU, levels of impulsivity, levels of aggression, and symptoms of psychopathology varied by ethnicity. There was a significant effect of ethnicity on symptoms of PVGU $[\mathrm{F}(4,877)=9.16, p=.000]$, academic delay of gratification $[\mathrm{F}(4,869)=4.12, p=.003]$, aggression $[\mathrm{F}(4,872)=7.93, p=.000]$, symptoms of depression $[\mathrm{F}(4,868)=4.15, p=.002]$, sensation seeking $[\mathrm{F}(4,871)=3.93, p=.004]$, state anxiety $[\mathrm{F}(4,859)=3.13, p=.014]$, and trait anxiety $[\mathrm{F}(4,858)=2.93, p=.020]$. Consequently, ethnicity was included as a covariate in all of the following analyses in which the aforementioned variables served as the dependent variable of interest. Results for ANOVA tests for both gender and ethnicity are presented in Table 3.

\section{ANCOVA Analyses for Video Game Genre Preference and Psychosocial Outcomes}

Multiple ANCOVA analyses were conducted to determine whether participants differed on symptoms of PVGU, levels of impulsivity, levels of aggression, and symptoms of psychopathology according to their reported preference for a particular genre of video game. Participants were classified according to their reported preference for Massively Multiplayer Online Role-Playing Games (MMORPG; $n=32$ ) and First-Person Shooters (FPS; $n=383$ ). These categories were not mutually exclusive (i.e., a participant could be classified as having a preference for both types of games).

There was a significant effect of preference for MMORPG on symptoms of PVGU $[F(1,718)=$ 22.43, $\left.p=.000, n_{p}{ }^{2}=.030\right]$ where those who preferred MMORPG reported more symptoms of PVGU ( $M$ $=3.52, S D=2.22)$ than those who did not identify a preference for MMORPG $(M=2.02, S D=1.69)$.

There was a significant effect of preference for FPS on sensation seeking $[F(1,720)=9.80, p=$ $\left..002, n_{p}{ }^{2}=.013\right]$ where those who preferred FPS reported higher levels of sensation seeking $(M=20.34$, $S D=5.84)$ than those who did not identify a preference for FPS $(M=17.70, S D=6.20)$. Results of ANCOVA analyses examining whether psychosocial outcome variables differed according to preference for both MMORPG and FPS are presented in Table 4. 


\section{Regression Analyses for PVGU as Predictor of Impulsivity, Aggression, and Psychopathology}

Several regression analyses were conducted to test whether symptoms of PVGU served as a predictor of impulsivity, aggression, and symptoms of other psychopathology. Participants who endorsed more symptoms of PVGU also reported increased levels of impulsivity measured via the BIS-11 $\left[R^{2}=.033\right.$, $F(2,871)=15.066, p=.000]$, increased levels of aggression $\left[R^{2}=.101, F(3,872)=32.498, p=.000\right]$, greater symptoms of depression $\left[R^{2}=.028, F(2,869)=19.343, p=.000\right]$, increased levels of state anxiety $\left.\left[R^{2}=.028\right), F(2,861)=12.547, p=.000\right]$, and increased levels of trait anxiety $\left[R^{2}=.040, F(2,860)=\right.$ 17.827, $p=.000]$. Results of regression analyses for PVGU as predictor of psychosocial outcomes are reported in Table 5 .

\section{Video Game Genre as Moderator of PVGU and Psychosocial Outcomes}

Pearson correlational analyses were conducted to identify which psychosocial outcome variables were significantly related to symptoms of PVGU and would therefore be appropriate for further moderator regression analyses. Pearson correlational analyses identified academic delay of gratification $(r=-.100, n$ $=874, p=.003)$, impulsivity measured via the BIS-11 $(r=.160, n=875, p=.000)$, aggression $(r=.268, n$ $=877, p=.000)$, symptoms of depression $(r=.169, n=873, p=.000)$, levels of state anxiety $(r=.153, n$ $=864, p=.000)$, and levels of trait anxiety $(r=.189, n=863, p=.000)$ as significantly related to symptoms of PVGU. The correlation matrix is presented in Table 6.

Moderator regression analyses were conducted in order to examine the roles of preference for video game genre (i.e., MMORPG or FPS), symptoms of PVGU, and their interaction in the prediction of impulsivity measured via the BIS-11, aggression, symptoms of depression, state anxiety, and trait anxiety. All regression models including the interaction of preference for video game genre and symptoms of PVGU were nonsignificant. Results for moderator regression analyses for preference for either MMORPG or FPS, symptoms of PVGU, and their interaction as predictors of psychosocial outcome variables are presented in Table 7. 


\section{CONCLUSIONS}

Although it has been previously established that PVGU is related to various psychosocial outcomes, not much is known about whether the genre of video game played most often by the gamer influences the aforementioned relationships. The current study sought to expand upon our knowledge of this relationship by investigating the role of preference for a particular genre of video game as a moderator of the relationship between symptoms of PVGU and levels of impulsivity, levels of aggression, and symptoms of general psychopathology in a sample of undergraduate students. In the current study, sensation seeking and delay of gratification (specifically in the domain of academic pursuits) were included as additional facets of impulsivity. General psychopathology was assessed via a measure of depression and a measure of state and trait anxiety. The current study focused on two specific video game genres and their potential roles as moderators of the relationship between PVGU and psychosocial outcome variables: MMORPGs and FPSs. These genres were chosen based on previous research findings concerning their relationship with the psychosocial outcomes of interest in the current study.

\section{PVGU and Psychosocial Outcomes}

Based on previous findings, it was hypothesized that reported symptoms of PVGU would be positively related to levels of impulsivity (Liau et al., 2011; Meerkerk et al., 2010; Gentile et al., 2012), aggression Kim et al., 2008; Gentile et al., 2011), and symptoms of other psychopathology (Shapira et al., 2000, Gentile et al., 2011).

Consistent with our hypothesis, analyses revealed that symptoms of PVGU indeed served as a predictor of impulsivity measured via the BIS-11 insofar that participants who endorsed a greater number of symptoms of PVGU also reported higher levels of impulsivity. These results are supported by previous research establishing a relationship between symptoms of PVGU and impulsivity (Liau et al., 2011; Meerkerk et al., 2010; Gentile et al., 2012; Chiu, Lee, \& Huang, 2004). One possible explanation for these results is that users who experience high levels of impulsivity may be more vulnerable to developing symptoms of PVGU. However, this is not to say that impulsivity will necessarily lead to the development of PVGU - rather, users who engage in video game use and who are high on impulsivity are at more risk to develop pathological use. 
In Davis' (2004) cognitive-behavior model of PTU, he suggests that one aspect of the development of PTU involves distal causes, such as underlying psychopathology, that are not in and of themselves responsible for the development of symptoms of PTU, but play some key role in its etiology. Given the amount of research suggesting a link between impulsivity and PVGU, it is possible that impulsivity may be one such factor that serves to predispose individuals to the development of PVGU. Individuals who are high on impulsivity may find it more difficult to inhibit their desire to spend more time or money on video games, which could result in many of the suggested symptoms of PVGU (e.g., could not stop playing video games, spent more money than was affordable on video games). Additionally, video games as a form of entertainment often provide numerous, rapidly changing visual stimuli which may make it particularly difficult for individuals who are high on impulsivity to inhibit their desire to play due to the rewarding aspects of the games.

However, it may also be possible that the relationship between PVGU and impulsivity is bidirectional. One of the few longitudinal studies of PVGU and impulsivity to date (Gentile et al., 2012) found that children who were exposed to greater levels of video game play also experienced greater problems with attention and impulsivity later on, even when controlling for earlier levels of both attention and impulsivity. This would suggest that the relationship between impulsivity and PVGU may be bidirectional (Gentile et al., 2012). Similar to the explanations noted above, it may be possible that an individual who at first engages in a healthy amount of video game play may be at greater risk to develop pathological symptoms later on if they also possess deficits in attention and high levels of impulsivity. Perhaps these aspects of their personality draw them toward a more pathological pattern of use (e.g., continually seeking out the rewarding aspects of video game play at the cost of functioning in other areas of life). However, in addition to impulsivity serving as a risk factor for PVGU, there may be some aspects of video game play that then cause the individual to become even more impulsive over time as their use becomes pathological. One possibility is that individuals are often rewarded in video games for responding rapidly to stimuli presented in the game (e.g., shooting an enemy before he shoots you), thereby reinforcing rapid responding and quick decision making without significant forethought. 
Additionally, symptoms of PVGU were also significantly related to levels of aggression.

Specifically, participants who endorsed a greater number of symptoms of PVGU also reported higher levels of aggression. These results replicate findings from other studies demonstrating a relationship between PVGU and aggression (Gentile 2011 et al.; Kim et al., 2008; Lemmens, Valkenburg, \& Peter, 2010). Similar to the results concerning impulsivity, there is some evidence to suggest that this relationship is also bidirectional such that higher levels of aggression may make individuals more prone to developing a pathological pattern of use, while at the same time a pathological pattern of use may lead to higher levels of aggression.

In terms of psychological characteristics that may predispose individuals to the development of PVGU, Kim and colleagues (2008) identified aggression, self-control, and narcissistic personality traits as factors that may serve as predictors PVGU. According to another study (Gentile et al., 2011), as players become more pathological in their use over time, they begin to be exposed to more violent video games. After repeated exposure to violent video games, players begin to harbor more normative beliefs about aggression, experience aggressive fantasies, and become more likely to express aggressive behaviors (Gentile et al., 2011). Individuals who already possess some aggressive qualities may be drawn to violent video games due to their ability to allow aggressive players to live out their aggressive fantasies in a fictional world, which may be reinforcing to them. This aggressiveness may be a contributing risk factor to PVGU, which in turn results in the players being exposed to a greater deal of violent video games, which in turn may reinforce their aggressive qualities by rewarding aggressive gameplay.

Also consistent with our hypothesis, symptoms of PVGU served as a predictor of symptoms of depression such that participants who endorsed a greater number of symptoms of PVGU also reported experiencing a greater number of symptoms of depression. These results supported previous research identifying a relationship between PTU and depression (Yoo et al., 2004; Gentile et al., 2011; Sim et al., 2012; Mentzoni et al., 2011). Like aggression and impulsivity, this relationship may also be bidirectional in nature. For example, previous research has established a link between experiencing loneliness and higher levels of depression in both children (Qualter, Brown, Munn, \& Rotenberg, 2010) and adult college students (Joiner, 1997). Additionally, researchers have also found that loneliness can be both a 
consequence and a predictor of PVGU (Lemmens, Valkenburg, \& Peter, 2010). Players may seek out online video games as a way to connect with other people online if they experience a dearth of social relationships in the real-world. Lemmens, Valkenburg, and Peter (2010) also suggest that PVGU might lead users to displace real-world social interactions and may lead to the deterioration of existing relationships, leading to increased feelings of loneliness, which in turn may lead to higher levels of depression.

Symptoms of PVGU served as a predictor of anxiety such that participants who endorsed a greater number of symptoms of PVGU also reported higher levels of both state and trait anxiety, a finding that is consistent with previous research (Mentzoni et al., 2011). Analyzing these results in light of the cognitive-behavior model of PTU (Davis, 2001), it is possible that high levels of anxiety may be an underlying psychopathology that predisposes individuals to become more pathological in their use of video games. Given the previous discussion of the experience of flow as a motivational mechanism for players (Chou \& Ting, 2003), it is possible that those who are high on anxiety may find the experience of flow particularly rewarding, thereby reinforcing their continued use of video games to the point of developing symptoms of PVGU.

\section{Preference for Video Game Genre and Psychosocial Outcomes}

Multiple ANCOVA analyses were conducted in order to determine whether self-reported preference for a particular genre of video game (either MMORPG or FPS) was related to symptoms of PVGU, symptoms of other psychopathology, levels of impulsivity, and levels of aggression. Based off of previous research concerning PVGU, MMORPG, aggression, and impulsivity (Collins et al., 2012), it was hypothesized that participants who reported a preference for MMORPG would report a greater number of symptoms of PVGU and other psychopathology, higher levels of aggression, and lower levels of impulsivity than individuals who did not report a preference for this genre. Data analyses revealed that a reported preference for MMORPG was only related to symptoms of PVGU insofar that participants who reported a preference for MMORPG were more likely to report more symptoms of PVGU than those who did not report a preference for MMORPG. This specific finding, that preference for MMORPG is related to symptoms of PVGU, may be explained by several of the potentially addictive characteristics of 
MMORPG identified by Charlton and Danforth (2009): the use of an operant conditioning variable-ratio reinforcement schedule for gameplay rewards, and the use of social reinforcement that players receive from other players as a result of achieving progress within the game. The findings regarding preference for MMORPG, impulsivity, aggression, and other psychopathology were not statistically significant suggesting that preference for this particular genre may not be associated with the aforementioned psychosocial variables. Additionally, some alternative explanations for this null finding are offered in the limitations section below.

It was hypothesized that participants who reported a preference for FPS would report a greater number of symptoms of PVGU, higher levels of impulsivity, higher levels of aggression, and a greater number of symptoms of other psychopathology than individuals who did not report a preference for this genre. Data analyses revealed that preference for FPS was only related to sensation seeking, a facet thought to be related yet distinct from impulsivity, such that participants who reported a preference for FPS were more likely to score higher on sensation seeking than those who did not report a preference for FPS. In its conception, sensation seeking has been described as "the need for varied, novel, and complex sensations and experiences" (Zuckerman, 1978). The FPS often places players in an environment that is constantly shifting, providing new sensations and experience that one must track - new enemies entering the battlefield, objective points changing mid-mission, surprise maneuvers by enemy combatants. It may be that individuals who are prone to sensation seeking find these types of environments within the game particularly rewarding such that they feel their need for sensation, so much so that their sensation seeking behavior predisposes them to developing a pathological level of use. The findings regarding preference for FPS, aggression, and other psychopathology were not statistically significant - suggesting that preference for this particular genre may not be associated with the aforementioned psychosocial variables. Additionally, some alternative explanations for this null finding are offered in the limitations section below.

\section{Moderating Effects of Preference for Video Game Genre}

The current study seeks to answer the question of whether preference for a particular genre of video, specifically MMORPG and FPS, moderates the relationship between symptoms of PVGU and 
impulsivity, aggression, and symptoms of other psychopathology. It was hypothesized that individuals who both (a) expressed a preference for MMORPG and (b) reported a greater number of symptoms of PVGU would be more likely to report higher levels of aggression and general psychopathology, but lower levels of impulsivity than those who do not prefer MMORPGs. A similar moderator relationship was thought to exist where individuals who expressed a preference for FPS and reported a greater number of symptoms of PVGU would be more likely to report higher levels of impulsivity, aggression, and general psychopathology.

Moderator regression analyses did not provide support for this hypothesis. One possible explanation for this finding is that preference for a particular video game genre does not act as a moderator of the relationship between symptoms of PVGU and the aforementioned psychosocial variables.

Alternatively, as discussed further in the limitations section, the methodology used to collect information regarding preference for video game genre may not have sufficiently tapped the supposed construct.

\section{Limitations}

Although the current study is the first to investigate the role of preference for video game genre as a moderator of the relationship between PVGU and psychosocial outcomes, there are a number of limitations that must be considered. One limitation is that the sample for the study was drawn solely from an undergraduate student population, which may limit the generalizability of the results to gamers at large considering the growing diversity of gamers in terms of age, ethnicity, and gender. In terms of age, the average participant was approximately 20 -years-old and no participants under the age of 18 were included in the study. In terms of ethnicity, the majority of participants identified as white. These limitations in terms of age and ethnicity may limit the generalizability of these results to gamer populations at large.

Another limitation of the study may lie in the nature of how preference for video game genre was assessed. In the current study, participants rated their three favorite video games, which were later classified according to genre and used to code the participant as having a preference for a genre or not. However, this prompt may be insufficiently specific in terms of how much information it can provide regarding how the participant spends the majority of their time playing video games. For example, an individual may report an older video game that they have not played for several years as one of their 
favorite video games - their tastes in genre of video game may have changed since then, substantially altering their experience with video games over time. Additionally, this approach to measuring preference for a genre of video game does not directly assess how much actual time the participant is devoting to that specific genre of video game - which may be a more relevant factor than just general like or dislike of a genre. Although it may be reasonable to conclude that someone who reports having a favorite video game in a particular genre would likely engage in several other games within that same genre, thereby increasing their exposure to the unique aspects of that genre that may influence behavior, there may be more appropriate means for assessing this construct.

Finally, video game genres can be difficult to distinguish from one another - with several games possessing a great degree of overlap between several difficult genres. For example, a video game may have aspects of both FPS and MMORPG video games and these aspects may have unique effects on behavior - some of which may even be conflicting. Classifying a game as one genre for the purpose of analyzing the effects of said genre may therefore be problematic.

\section{Future Research}

Future research should strive to continue to investigate the potential moderating effects of genre of video game on the relationship between symptoms of PVGU and psychosocial outcomes. The current study is an initial exploratory examination of the possible effects of video game genre on the aforementioned relationship, and future research may benefit by addressing the limitations noted above to further refine the results of this study. Future research should seek to obtain a more diverse sample in terms of age and ethnicity - especially considering the clinical implications of identifying patterns of pathological use of video games in younger adolescents, a time in which individuals may be more susceptible to developing negative lifelong habits that have long-lasting effects. Additionally, future research may also benefit from reevaluating the current study's approach to classifying participants according to preference for video game genre. A more theoretically useful measurement might involve asking participants to directly report on how much time they spend playing a particular genre during a given week. A more accurate measurement of participant exposure to a particular genre of video games may provide different results opposed to those reported above. 


\section{Conclusions}

The findings of the current study do not support the notion that preference for a particular video game genre such as MMORPGs or FPS serves as a moderator of the relationship between pathological video game use and psychosocial outcomes. Although these results may merely reflect that video game genre does not serve as a moderator of the aforementioned relationship, it is also possible that these nonsignificant results are attributable to some of the measurement limitations concerning video game genre discussed above. It would be useful for future researchers to expand upon the findings of this study by employing a different approach for measuring exposure to a particular genre of video games.

Furthermore, our findings regarding the relationship between PVGU and psychosocial outcomes replicates previous findings in these areas insofar that gamers who endorse a higher number of symptoms of PVGU also tended to endorse higher levels of impulsivity, levels of aggression, more symptoms of depression, and report higher levels of both state and trait anxiety. 


\section{REFERENCES}

American Psychiatric Association (1994). Diagnostic and statistical manual of mental disorders ( $4^{\text {th }}$ ed.). Washington, DC: Author.

American Psychiatric Association (2000). Diagnostic and statistical manual of mental disorders $\left(4^{\text {th }}\right.$ ed., text rev.). Washington, DC: Author.

American Psychiatric Association (2013). Diagnostic and statistical manual of mental disorders (5 ${ }^{\text {th }}$ ed.). Washington, DC: Author.

Ballard, M., Melissa, G., Reilly, J., \& Noggle, M. (2009). Correlates of video game screen time among males: Body mass, physical activity, and other media use. Eating Behaviors, 10, 161-167.

Barlett, C. P., Harris, R. J., \& Baldassaro, R. (2007). Longer you play, the more hostile you feel: Examination of first person shooter video games and aggression during video game play. Aggressive Behavior, 33(6), 486-497.

Bembenutty, H. (1999). Sustaining motivation and academic goals: The role of academic delay of gratification. Learning and Individual Differences, 11, 233-257.

Bembenutty, H., \& Kaabenick, S. A. (2004). Inherent association between academic delay of gratification, future time perspective, and self-regulated learning. Educational Psychology Review, 16, 35-57.

Black, D. W., Belsare, G., \& Schlosser, S. (1990). Clinical features, psychiatric comorbidity, and healthrelated quality of life in persons reporting compulsive use behavior. J of Clinical Psychiatry, 60(12), 839-844.

Blaszczynski, A. (2006). Internet use: In search of an addiction. Int J of Mental Health and Addiction, 4(1), 7-9.

Bushman, B. J., \& Anderson, C. A. (2002). Violent video games and hostile expectations: A test of the general aggression model. Personality and Social Psychology Bulletin, 28(12), 1679-1686.

Buss, A. H., \& Perry, M. (1992). Personality processes and individual differences: The aggression questionnaire. J of Personality and Social Psychology, 63(3), 452-459. 
Charlton, J. P., \& Danforth, I. D. W. (2009). Validating the distinction between computer addiction and engagement: Online game playing and personality. Behavior \& Information Technology, 29(6), 601-613.

Chiu, S. I., Lee, J. Z., \& Huang, D. H. (2004). Video game addiction in children and teenagers in Taiwan. CyberPsychology \& Behavior, 7(5), 571-581.

Chou, T. J., \& Ting, C. C. (2003). The role of flow experience in cyber-game addiction. CyberPsychology \& Behavior, 6(6), 663-675.

Collins, E., Freeman, J., \& Chamarro-Premuzic, T. (2012). Personality traits associated with problematic and non-problematic massively multiplayer online role playing game use. Personality and Individual Differences, 52(2), 133-138.

Csikszentmihalyi, M. (1990). Flow: the psychology of optimal experience. New York: Harper and Row.

Davis, R. A. (2001). A cognitive-behavioral model of pathological Internet use. Computers in Human Behavior, 17(2), 187-195.

Desai, R. A., Krishnan-Sarin, S., Cavallo, D., \& Potenza, M. N. (2010). Video-gaming among high school students: Health correlates, gender differences, and problematic gaming. Pediatrics, 126(6), e1414-e1424.

Dunn, O. J. (1961). Multiple comparison among means. J of American Statistical Association, 56, 52-64.

Durkin, K., \& Barber, B. (2002). Not so doomed: Computer game play and positive adolescent development. Applied Developmental Psychology, 23, 373-392.

Entertainment Software Association (2013). 2014 Sales, demographic, and usage data: Essential facts about the computer and video game industry. Entertainment Software Association. Retrieved from http://www.theesa.com/facts/pdfs/esa_ef_2013.pdf

Foo, C. Y., \& Koivisto, E. M. (2004, September). Defining grief play in MMORPGs: player and developer perceptions. In Proceedings of the 2004 ACM SIGCHI International Conference on Advances in computer entertainment technology (pp. 245-250). ACM.

Gentile, D. A. (2009). Pathological video-game use among youth ages 8 to 18: A national study. Psychological Science, 20(5), 594-602. 
Gentile, D. A., Choo, H., Liau, A., Sim, T, Li, D., Fung, D., \& Khoo, A. (2011). Pathological video game use among youths: A two-year longitudinal study. Pediatrics, 127(2), e319-e329.

Gentile, D. A., Lynch, P. J., Linder, J. R., \& Walsh, D. A. (2004). The effects of violent video game habits on adolescent hostility, aggressive behaviors, and school performance. J of Adolescence, 27, 5-22.

Gentile, D. A., Swing, E. L., Lim, C. G., \& Khoo, A. (2012). Video game playing, attention problems, and impulsiveness: Evidence of bidirectional causality. Psychology of Popular Media Culture,1(1), 62.

Graham, L. (2009). The NPD group: More Americans play video games than go out to the movies. NPD Group. Retrieved from https://www.npd.com/wps/portal/npd/us/news/press-releases/pr_090520/

Griffiths, M. D., Davies, M. N., \& Chappell, D. (2004). Online computer gaming: a comparison of adolescent and adult gamers. $J$ of Adolescence, 27(1), 87-96.

Holden, C. (2001). "Behavioral” addictions: Do they exist? Science, 294(5544), 980-982.

Joiner Jr, T. E. (1997). Shyness and low social support as interactive diatheses, with loneliness as mediator: Testing an interpersonal-personality view of vulnerability to depressive symptoms. $J$ of Abnormal Psychology, 106(3), 386.

Karmali, L. (2013). World of Warcraft down to 7.7 million subscribers. IGN Entertainment. Retrieved from http://www.ign.com/articles/2013/07/26/world-of-warcraft-down-to-77-million-subscribers

Kim, E. J., Namkoong, K., Ku, T., \& Kim, S. J. (2008). The relationship between online game addiction and aggression, self-control and narcissistic personality traits. European Psychiatry, 23(3), 212218.

King, D. L., Delfabbro, P. H., \& Zajac, I. T. (2011). Preliminary validation of a new clinical tool for identifying problem video game playing. Int J of Mental Health and Addiction, 9(1), 72-87.

King, D. L., Haagsma, M. C., Delfabbro, P. H., Gradisar, M., \& Griffiths, M. D. (2013). Toward a consensus definition of pathological video-gaming: A systematic review of psychometric assessment tools. Clinical psychology review, 33(3), 331-342. 
Kuss, D. J., \& Griffiths, M. D. (2012). Internet gaming addiction: A systematic review of empirical research. Int J of Mental Health and Addiction, 10(2), 278-296.

Liau, A. K., Neo, E. C., Gentile, D. A., Choo, H., Sim, T., Li, D., \& Khoo, A. (2011). Impulsivity, selfregulation, and pathological video gaming among youth: Testing a mediation model. Asia-Pacific J of Public Health, doi: 10.1177/1010539511429369

Meerkerk, G. J., van den Eijnden, R. J., Franken, I. H. A., \& Garretsen, H. F. L. (2010). Is compulsive internet use related to sensitivity to reward and punishment, and impulsivity?. Computers in Human Behavior, 26(4), 729-735.

Mentzoni, R. A., Brunborg, G. S., Molde, H., Myrseth, H., Skouverøe, K. J. M., Hetland, J., \& Pallesen, S. (2011). Problematic video game use: estimated prevalence and associations with mental and physical health. Cyberpsychology, Behavior, and Social Networking, 14(10), 591-596.

Patton, J. H., Stanford, M. S., \& Barrat, E. S. (1995). Factor structure of the Barrat Impulsiveness Scale. J of Clinical Psychology, 6, 768-774.

Peters, C. S., \& Malesky Jr, L. A. (2008). Problematic usage among highly-engaged players of massively multiplayer online role playing games. CyberPsychology \& Behavior, 11(4), 481-484.

Petry, N. M., Rehbein, F., Gentile, D. A., Lemmens, J. S., Rumpf, H. J., MoBle, T., ... \& O’Brien, C. P. (2014). An international consensus for assessing internet gaming disorder using the new DSM-5 approach. Addiction. doi:10.1111/add.12457

Pickens, R. W., \& Svikis, D. S. (1988). Biological vulnerability to drug abuse (Vol. 89). US Department of Health and Human Services, Public Health Service, Alcohol, Drug Abuse, and Mental Health Administration, National Institute on Drug Abuse.

Qualter, P., Brown, S. L., Munn, P., \& Rotenberg, K. J. (2010). Childhood loneliness as a predictor of adolescent depressive symptoms: an 8-year longitudinal study. European Child \& Adolescent Psychiatry, 19(6), 493-501.

Radloff, L. S. (1977). The CES-D Scale: A self-report depression scale for research in the general population. Applied Psychological Measurement, 1, 385-401. 
Ryan, R. M., Rigby, C. S., \& Przybylski, A. (2006). The motivational pull of video games: A selfdetermination theory approach. Motivation and emotion, 30(4), 344-360.

Schneider, E. F. (2004). Death with a Story. Human Communication Research, 30(3), 361-375.

Shafer, A. B. (2006). Meta-analysis of the factor structures of four depression questionnaires: Beck, CESD, Hamilton, and Zung. J of Clinical Psychology, 62(1), 123-146.

Shapira, N. A., Goldsmith, T. D., Keck Jr, P. E., Khosla, U. M., \& McElroy, S. L. (2000). Psychiatric features of individuals with problematic internet use. J of Affective Disorders, 57(1), 267-272.

Shapira, N. A., Lessig, M. C., Goldsmith, T. D., Szabo, S. T., Lazoritz, M., Gold, M. S., \& Stein, D. J. (2003). Problematic internet use: proposed classification and diagnostic criteria. Depression and Anxiety, 17(4), 207-216.

Sim, T., Gentile, D. A., Bricolo, F., Serpelloni, G., \& Gulamoydeen, F. (2012). A conceptual review of research on the pathological use of computers, video games, and the Internet. Int J of Mental Health Addiction, 10, 748-769.

Spielberger, C. D., Gorsuch, R. L., \& Lushene, R. E. (1970). Manual for the State-Trait Anxiety Inventory. Palo Alto, CA: Consulting Psychologists Press.

Stanford, M. S., Mathias, C. W., Dougherty, D. M., Lake, S. L., Anderson, N. E., \& Patton, J. H. (2009). Fifty years of the Barrat Impulsiveness Scale: An update and review. Personality and Individual Differences, 47, 385-395.

Wallace, P. (1999). The psychology of the Internet. Cambridge University Press.

Weaver, J. B., Mays, D., Weaver, S. B., Kannenberg, W., Hopkins, G. L., Eroglu, D., \& Bernhardt, J. M. (2009). Health-risk correlates of video-game playing among adults. American J of Preventative Medicine, 37(4), 299-305.

White, M. M. (2012). New tutorials for digital games: game design meets instructional design (Doctoral dissertation, Memorial University of Newfoundland).

Williams, D., Ducheneaut, N., Xiong, L., Zhang, Y., Yee, N., \& Nickell, E. (2006). From tree house to barracks: The social life of guilds in World of Warcraft. Games \& Culture, 1(4), 338-361. 
Wood, R. (2008). Problems with the concept of video game "addiction": Some case study examples. Int J of Mental Health Addiction, 6, 169-178.

Yee, N. (2006). Motivations for play in online games. CyberPsychology \& Behavior, 9(6), 772-775.

Yoo, H. J., Choo, S. C., Ha, J., Yune, S. K., Kim, S. J., Hwang, J., et al. (2004). Attention deficit hyperactivity symptoms and internet addiction. Psychiatry and Clinical Neurosciences, 58(5), 487-494.

Young, K. S. (1998). Internet addiction: The emergence of a new clinical disorder. CyberPsychology \& Behavior, 1(3), 237-244.

Zuckerman, M., Eysenck, S, \& Eysenck, H. J. (1978). Sensation seeking in England and America: Crosscultural, age, and sex comparisons. J of Consulting and Clinical Psychology, 46(1), 139-149. 


\section{APPENDIX}

Table 1 Gender and Ethnicity Sample Information

$\mathrm{N}$

Percentage

Gender

Female

401

54.5

Male

480

45.5

Ethnicity

European American

696

78.9

Asian American / Pacific Islander

83

9.4

Other

38

4.3

Latino / Hispanic American

36

4.1

African American

29

3.3

(Missing $n=50$ ) 
Table 2 Regression Analyses: Age as Predictor of Psychosocial Variables

\begin{tabular}{lcccc}
\hline & $R^{2}$ & $F(d f)$ & $p$ & $\beta$ \\
\hline PVGU & .008 & $6.80(1,880)$ & $.009^{*}$ & .068 \\
ADOGS & .009 & $8.224(1,872)$ & $.004^{*}$ & .199 \\
BIS-11 & .006 & $4.905(1,872)$ & $.027^{*}$ & -.324 \\
AQ & .001 & $.470(1,874)$ & .493 & -.300 \\
CES-D & .003 & $3.033(1,870)$ & .082 & -.263 \\
SSS & .002 & $1.668(1,873)$ & .197 & -.118 \\
STAIX-State & .000 & $.000(1,862)$ & .984 & -.003 \\
STAIX-Trait & .003 & $2.869(1,861)$ & .091 & -.245 \\
\hline
\end{tabular}


Table 3 ANOVA for Gender and Ethnicity x Psychosocial Variables

\begin{tabular}{|c|c|c|c|}
\hline & $F(d f)$ & $p$ & $n_{p}^{2}$ \\
\hline \multicolumn{4}{|l|}{ Gender } \\
\hline PVGU & $149.794(1,879)$ & $.000 * *$ & .146 \\
\hline ADOGS & $23.830(1,871)$ & $.000 * *$ & .027 \\
\hline BIS-11 & $2.615(1,872)$ & .106 & .003 \\
\hline $\mathrm{AQ}$ & $34.009(1,874)$ & $.000 * *$ & .037 \\
\hline CES-D & $2.045(1,870)$ & .153 & .002 \\
\hline SSS & $58.842(1,873)$ & $.000 * *$ & .063 \\
\hline STAIX-State & $2.263(1,861)$ & .133 & .003 \\
\hline STAIX-Trait & $3.741(1,860)$ & .053 & .004 \\
\hline \multicolumn{4}{|l|}{ Ethnicity } \\
\hline PVGU & $9.158(4,877)$ & $.000 * *$ & .040 \\
\hline ADOGS & $4.120(4,869)$ & $.003 *$ & .019 \\
\hline BIS-11 & $2.050(4,870)$ & .085 & .009 \\
\hline AQ & $7.934(4,872)$ & $.000 * *$ & .035 \\
\hline CES-D & $4.145(4,868)$ & $.002 *$ & .019 \\
\hline SSS & $3.933(4,871)$ & $.004 *$ & .018 \\
\hline STAIX-State & $3.127(4,859)$ & $.014 *$ & .014 \\
\hline STAIX-Trait & $2.930(4,858)$ & $.020^{*}$ & .013 \\
\hline
\end{tabular}


Table 4 ANCOVA for Preference for Video Game Genre x Psychosocial Variables

\begin{tabular}{|c|c|c|c|}
\hline & $F(d f)$ & $p$ & $n_{p}^{2}$ \\
\hline \multicolumn{4}{|c|}{ Preference for MMORPG } \\
\hline PVGU & $22.429(1,718)$ & $.000 * *$ & .030 \\
\hline ADOGS & $1.446(1,715)$ & .230 & .002 \\
\hline BIS-11 & $.780(1,719)$ & .377 & .001 \\
\hline AQ & $.335(1,720)$ & .563 & .000 \\
\hline CES-D & $.001(1,718)$ & .978 & .000 \\
\hline SSS & $6.249(1,718)$ & $.013^{*}$ & .009 \\
\hline STAIX-State & $1.724(1,713)$ & .190 & .002 \\
\hline STAIX-Trait & $1.005(1,712)$ & .316 & .001 \\
\hline \multicolumn{4}{|l|}{ Preference for FPS } \\
\hline PVGU & $1.274(1,719)$ & .259 & .002 \\
\hline ADOGS & $1.473(1,716)$ & .225 & .002 \\
\hline BIS-11 & $1.775(1,720)$ & .183 & .002 \\
\hline AQ & $2.510(1,721)$ & .114 & .003 \\
\hline CES-D & $.057(1,719)$ & .812 & .000 \\
\hline SSS & $9.802(1,719)$ & $.002 * *$ & .013 \\
\hline STAIX-State & $.134(1,714)$ & .714 & .000 \\
\hline STAIX-Trait & $.987(1,713)$ & .321 & .001 \\
\hline
\end{tabular}


Table 5 Regression Analyses: PVGU as Predictor of Psychosocial Outcome Variables

\begin{tabular}{lcccc}
\hline & $R^{2}$ & $F(d f)$ & $p$ & $\beta$ \\
\hline ADOGS & .057 & $13.124(4,868)$ & .051 & -.188 \\
BIS-11 & .033 & $15.066(2,871)$ & $.000^{* *}$ & .939 \\
AQ & .101 & $32.498(3,872)$ & $.000^{* *}$ & 3.347 \\
CES-D & .043 & $19.343(2,869)$ & $.000^{* *}$ & 1.251 \\
SSS & .077 & $24.224(3,871)$ & .658 & -.055 \\
STAIX-State & .028 & $12.547(2,861)$ & $.000^{* *}$ & .872 \\
STAIX-Trait & .040 & $17.827(2,860)$ & $.000^{* *}$ & .991 \\
\hline
\end{tabular}


Table 6 Means, Standard Deviations, and Correlations for Psychosocial Variables

\begin{tabular}{|c|c|c|c|c|c|c|c|c|}
\hline Variables & 1 & 2 & 3 & 4 & 5 & 6 & 7 & 8 \\
\hline 1. $\mathrm{PVGU}$ & & & & & & & & \\
\hline 2. ADOGS & $-.100 * *$ & & & & & & & \\
\hline 3. BIS-11 & $.160 * *$ & $-.379 * *$ & & & & & & \\
\hline 4. $\mathrm{AQ}$ & $.268 * *$ & $-.191 * *$ & $.373 * *$ & & & & & \\
\hline 5. CES-D & $.169 * *$ & $-.151 * *$ & $.324 * *$ & $.390 * *$ & & & & \\
\hline 6. SSS & .065 & $-.305^{* *}$ & $.311 * *$ & $.239 * *$ & .001 & & & \\
\hline 7. STAIX-State & $.153 * *$ & $-.147 * *$ & $.318 * *$ & $.335^{* *}$ & $.631 * *$ & -.002 & & \\
\hline 8. STAIX-Trait & $.189^{* *}$ & $-.174 * *$ & $.362 * *$ & $.392 * *$ & $.713 * *$ & -.036 & $.759 * *$ & \\
\hline Mean & 1.71 & 27.78 & 65.69 & 86.70 & 16.11 & 18.91 & 39.79 & 41.45 \\
\hline Standard Deviation & 1.77 & 4.71 & 9.90 & 29.61 & 10.22 & 6.18 & 10.83 & 9.76 \\
\hline
\end{tabular}


Table 7 Moderator Analyses for Preference for Interaction of Video Game Genre and PVGU x Psychosocial Outcome Variables

\begin{tabular}{|c|c|c|c|c|}
\hline & $R^{2}$ & $F(d f)$ & $p$ & $\beta$ \\
\hline \multicolumn{5}{|c|}{ Preference for MMORPG x PVGU } \\
\hline ADOGS & .087 & $11.314(6,713)$ & .369 & -.025 \\
\hline BIS-11 & .062 & $11.898(4,717)$ & .868 & .005 \\
\hline AQ & .107 & $17.132(5,718)$ & .044 & .057 \\
\hline CES-D & .066 & $12.671(4,716)$ & .812 & .007 \\
\hline STAIX-State & .039 & $7.293(4,711)$ & .706 & .011 \\
\hline STAIX-Trait & .059 & $11.084(4,710)$ & .444 & .022 \\
\hline \multicolumn{5}{|c|}{ Preference for FPS x PVGU } \\
\hline ADOGS & .087 & $11.324(6,714)$ & .975 & .001 \\
\hline BIS-11 & .062 & $11.945(4,718)$ & .066 & .066 \\
\hline AQ & .105 & $16.856(5,719)$ & .743 & .012 \\
\hline CES-D & .068 & $13.017(4,717)$ & .227 & .044 \\
\hline STAIX-State & .040 & $7.502(4,712)$ & .495 & .025 \\
\hline STAIX-Trait & .064 & $12.154(4,711)$ & .327 & .036 \\
\hline
\end{tabular}

